\title{
Reduction of Boron Diffusion in Silicon-Germanium by Fluorine Implantation
}

\author{
H. A. W. El Mubarek and P. Ashburn
}

\begin{abstract}
This letter investigates the effect of a $185 \mathrm{keV}$, $2.3 \times 10^{15} \mathrm{~cm}^{-2} \mathrm{~F}^{+}$implant on boron transient enhanced diffusion (TED) and boron thermal diffusion in SiGe by characterizing the diffusion of a boron marker layer in samples with and without a $288 \mathrm{keV}, 6 \times 10^{13} \mathrm{~cm}^{-2} \mathrm{P}^{+}$implant. In samples implanted with $\mathrm{F}^{+}$only, the fluorine suppresses boron thermal diffusion by $58 \%$. In samples given both $\mathrm{P}^{+}$and $\mathrm{F}^{+}$implants, the fluorine completely eliminates boron transient enhanced diffusion caused by the $\mathbf{P}^{+}$implant and also significantly reduces boron thermal diffusion. SIMS profiles after anneal show a fluorine concentration in the SiGe layer that is approximately $8 \times$ higher than after implant, indicating that fluorine accumulates in the SiGe layer during anneal. A comparison with fluorine profiles in comparable silicon samples also shows that the fluorine concentration after anneal is dramatically higher in SiGe samples than in Si samples. This accumulation of fluorine in the SiGe layer during anneal will have major benefits for boron diffusion suppression in devices like SiGe HBTs, where boron must be kept within the SiGe layer.
\end{abstract}

Index Terms-Boron diffusion, fluorine, SiGe heterjunction bipolar transistors (HBTs), transient enhanced diffusion (TED).

\section{INTRODUCTION}

$\mathbf{T}$ HE MINIMIZATION of boron diffusion is vitally important in all types of $\mathrm{Si}$ and $\mathrm{SiGe}$ devices [1]-[4]. For example, in SiGe HBTs diffusion of boron from the SiGe base creates parasitic energy barriers [2] that degrade the current gain and limit the value of cut-off frequency that can be achieved. Similarly, in MOSFETs diffusion of boron in the pocket [3] has detrimental consequences on short channel effects. Carbon incorporation has been used in SiGe HBTs to reduce boron diffusion [4], but it is not without disadvantages, for example increased base leakage at higher carbon concentrations [5].

Recently, fluorine implantation has been investigated as an alternative method of suppressing boron diffusion in silicon, and shown to be extremely effective, giving significantly lower boron diffusion in silicon [6]-[17]. Fluorine implantation has also been applied to MOSFETs and shown to give improved short channel effects by reducing boron diffusion in halo and extension regions [18], [19]. However, to the authors' knowledge, there have been no reports of the effects of fluorine on boron diffusion in SiGe. In this letter, a study is therefore made of the effect of fluorine on both boron thermal diffusion and boron transient enhanced diffusion (TED) in SiGe, and its potential for application in devices is discussed.

Manuscript received March 19 2004; revised May 26, 2004. This work was supported by the EPSRC. The review of this letter was arranged by Editor T.-J. King.

The authors are with the School of Electronics and Computer Science, University of Southampton, Southampton, SO17 1BJ, U.K.

Digital Object Identifier 10.1109/LED.2004.832530

\section{SAMPLE FABRICATION}

Low-pressure chemical vapor deposition at $800^{\circ} \mathrm{C}$ was used to grow layers analogous to those used in SiGe HBTs. Layers grown included a 400-nm Si starter layer, a 50-nm $\mathrm{Si}_{0.89} \mathrm{Ge}_{0.11}$ layer and a $130-\mathrm{nm}$ Si cap layer on a (100) silicon wafer. A boron-doped marker layer was incorporated within the $\mathrm{SiGe}$ layer with a peak concentration of $1.2 \times 10^{19} \mathrm{~cm}^{-3}$. Four types of samples were then produced from the same wafer; the first had no implants (unimplanted), the second had a phosphorus implant only $\left(\mathrm{P}^{+}\right.$implanted), the third had a phosphorus and a fluorine implant $\left(\mathrm{P}^{+}\right.$and $\mathrm{F}^{+}$implanted), and the fourth had a fluorine implant only ( $\mathrm{F}^{+}$implanted). A $288 \mathrm{keV}, 6 \times 10^{13} \mathrm{~cm}^{-2}$ phosphorus implant was used with an energy and dose similar to those used for selective implanted collectors. The $\mathrm{F}^{+}$was implanted at $185 \mathrm{keV}, 2.3 \times 10^{15} \mathrm{~cm}^{-2}$, with the energy chosen to give a fluorine peak coincident with the phosphorus peak. The samples were annealed by rapid thermal annealing in nitrogen at $1000{ }^{\circ} \mathrm{C}$ for $30 \mathrm{~s}$.

\section{RESUlTS AND DISCUSSION}

Fig. 1(a) shows boron secondary ion mass spectrometry (SIMS) profiles in samples implanted with $\mathrm{P}^{+}$only and with both $\mathrm{P}^{+}$and $\mathrm{F}^{+}$, followed by an anneal of $30 \mathrm{~s}$ at $1000{ }^{\circ} \mathrm{C}$. Boron and germanium profiles after growth are also shown for reference. In the sample implanted with $\mathrm{P}^{+}$only, the anneal significantly decreases the peak boron concentration in the SiGe layer from $1.2 \times 10^{19}$ to $3.2 \times 10^{18} \mathrm{~cm}^{-3}$ and gives considerable out-diffusion of the boron profile into the adjacent silicon layers. In contrast, in the sample implanted with both $\mathrm{P}^{+}$and $\mathrm{F}^{+}$, the decrease in peak boron concentration is smaller (from $1.2 \times 10^{19}$ to $7.3 \times 10^{18} \mathrm{~cm}^{-3}$ ) and the out-diffusion of the boron profile into the adjacent silicon layers is dramatically reduced. For comparison, Fig. 1(b) shows boron SIMS profiles in a sample implanted with $\mathrm{F}^{+}$only and an unimplanted sample after an anneal of $30 \mathrm{~s}$ at $1000{ }^{\circ} \mathrm{C}$. For the unimplanted sample, the anneal decreases the peak boron concentration in the SiGe layer from $1.2 \times 10^{19}$ to $4.7 \times 10^{18} \mathrm{~cm}^{-3}$ and gives significant out-diffusion of the boron profile into the adjacent silicon. In contrast for the $\mathrm{F}^{+}$implanted sample, the decrease in peak boron concentration in the SiGe layer is reduced (from $1.2 \times 10^{19}$ to $7.0 \times 10^{18} \mathrm{~cm}^{-3}$ ) and the out-diffusion of the boron profile is small. Comparing the distance diffused by the boron in the SiGe (substrate side of the boron peak) at a concentration of $1.3 \times 10^{18} \mathrm{~cm}^{-3}$, we find a $58 \%$ decrease in the boron thermal diffusion in $\mathrm{SiGe}$ in the $\mathrm{F}^{+}$implanted sample compared with the unimplanted sample $(5.2 \mathrm{~nm}$ compared with $12.5 \mathrm{~nm}$ ). A comparison of the boron profile for the $\mathrm{F}^{+}$ 


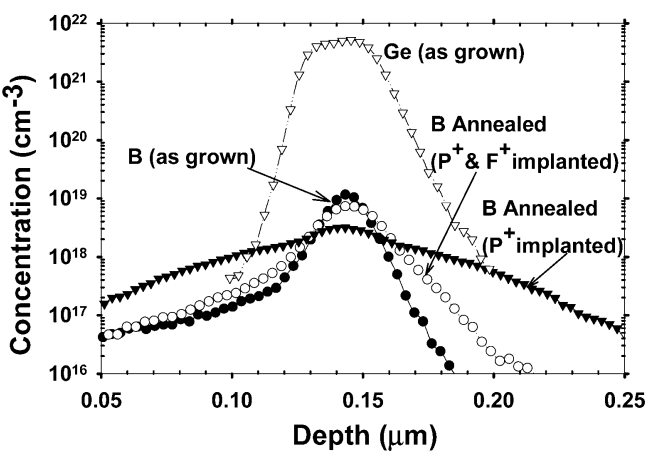

(a)

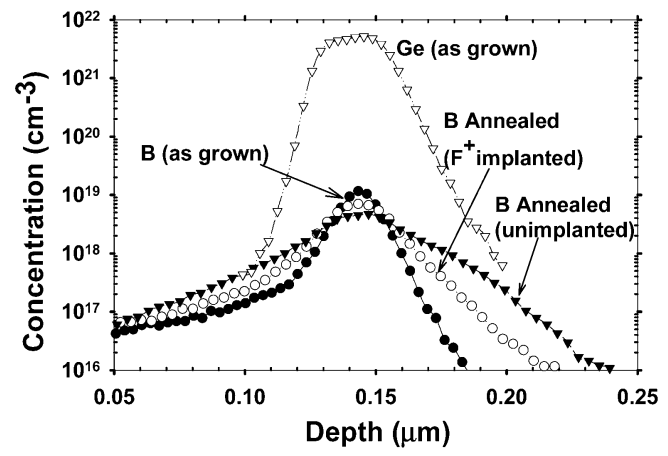

(b)

Fig. 1. Boron SIMS profiles in SiGe after growth and after anneal for $30 \mathrm{~s}$ at $1000{ }^{\circ} \mathrm{C}$. (a) Sample implanted with $\mathrm{P}^{+}$only and a sample implanted with both $\mathrm{P}^{+}$and $\mathrm{F}^{+}$. (b) Unimplanted sample and a sample implanted with $\mathrm{F}^{+}$only.

implanted sample in Fig. 1(b) with that for the $\mathrm{P}^{+}$and $\mathrm{F}^{+}$ implanted sample in Fig. 1(a) shows that the profiles are almost identical, indicating that the $\mathrm{F}^{+}$implant in the latter sample has not only completely eliminated boron TED resulting from the $\mathrm{P}^{+}$implant, but has also significantly reduced boron thermal diffusion.

Fig. 2 compares the as-implanted and annealed fluorine profiles for the sample implanted with $\mathrm{F}^{+}$only. The annealed fluorine profile is considerably different than the as-implanted profile and shows three peaks at depths of $0.14,0.41$, and $0.58 \mu \mathrm{m}$ and a shoulder extending from about 0.23 to $0.29 \mu \mathrm{m}$. The shallowest $\mathrm{F}^{+}$peak at a depth of $0.14 \mu \mathrm{m}$ is located completely within the SiGe layer and coincides with the boron profile. The broad peak at a depth of $0.41 \mu \mathrm{m}$ coincides approximately with the range of the fluorine implant $(0.41 \mu \mathrm{m})$. The deepest peak at a depth of $0.58 \mu \mathrm{m}$ coincides with the growth interface and is an artifact of the surface clean carried out prior to epitaxy. The integrated dose of the fluorine SIMS profile is $2.3 \times 10^{15} \mathrm{~cm}^{-2}$ after implant and $1.75 \times 10^{15} \mathrm{~cm}^{-2}$ after anneal, indicating that $24 \%$ of the fluorine has been lost during anneal. The fluorine profile in the sample implanted with both $\mathrm{P}^{+}$and $\mathrm{F}^{+}$is not shown but was very similar to that shown in Fig. 2.

The peak fluorine concentration in the SiGe layer after anneal in Fig. 2 is $7.6 \times 10^{19} \mathrm{~cm}^{-3}$, which is dramatically higher than that after implant $\left(1 \times 10^{19} \mathrm{~cm}^{-3}\right.$ at a depth of $\left.0.14 \mu \mathrm{m}\right)$. This result indicates that fluorine has been transported into the SiGe layer from the adjacent silicon during the anneal, where it has accumulated. It would be expected that this accumulation of fluorine in the SiGe layer would be an advantage for boron

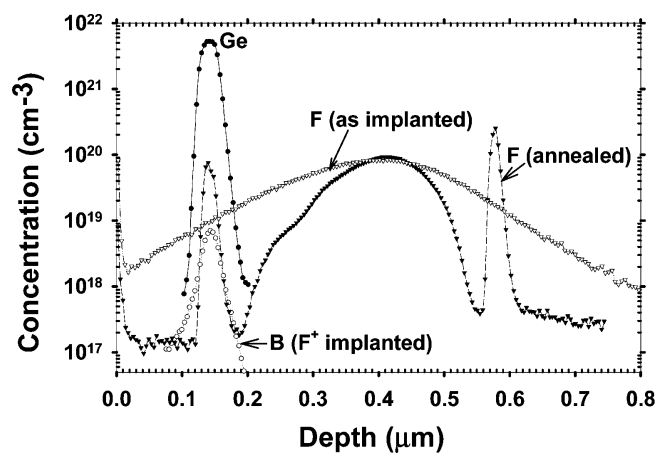

Fig. 2. Fluorine SIMS profiles in samples implanted with $\mathrm{F}^{+}$only after implant and after anneal for $30 \mathrm{~s}$ at $1000^{\circ} \mathrm{C}$. Boron and germanium profiles after $\mathrm{F}^{+}$implant and anneal are also shown for reference.

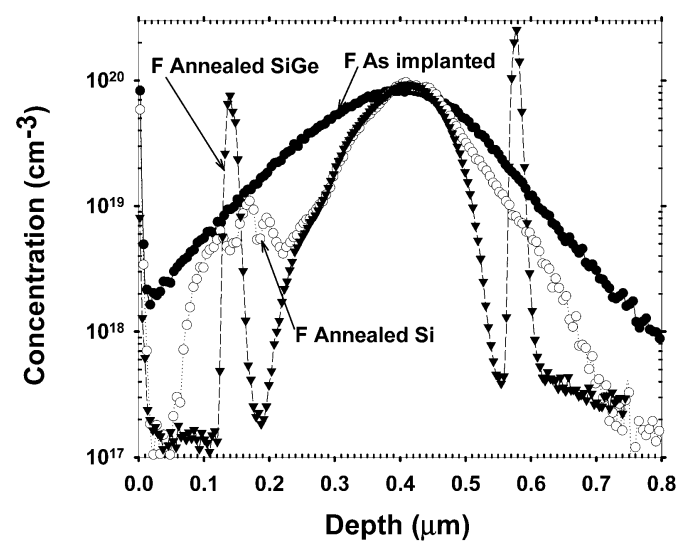

Fig. 3. Comparison of fluorine SIMS profiles in SiGe and Si samples after implant (at the same dose and energy) and anneal for $30 \mathrm{~s}$ at $1000{ }^{\circ} \mathrm{C}$.

diffusion suppression in devices such as SiGe HBTs, where the boron is located in the SiGe layer. To gain further insight into the effect of the SiGe layer on the fluorine profile, Fig. 3 compares the annealed fluorine profiles in $\mathrm{SiGe}$ and $\mathrm{Si}$ samples [17] implanted with the same dose and energy of fluorine. In the silicon sample, a fluorine peak can be seen in a similar position to that in the SiGe sample, but it is considerably broader, extending from about 0.05 to $0.22 \mu \mathrm{m}$, and at no point is the fluorine concentration higher than the as-implanted fluorine concentration. This result confirms that the accumulation of fluorine to concentrations much higher than the as-implanted concentration is due to the presence of the SiGe layer.

The $\mathrm{F}^{+}$implanted samples were examined using transmission electron microscopy both after implant and after an anneal of $30 \mathrm{~s}$ at $1000{ }^{\circ} \mathrm{C}$. The as-implanted micrographs showed that the $\mathrm{Si}$ and $\mathrm{SiGe}$ were not amorphized by the $\mathrm{F}^{+}$implant and the micrographs after anneal showed no defects in the SiGe layer. This result indicates that the fluorine peak in the SiGe layer is not due to trapping of fluorine at line defects. Hence if defects are responsible for the fluorine peak, they must be too small to resolve by TEM. The SiGe layer is located in the vacancy rich region of both the fluorine and phosphorus damage profiles [20], and, hence, one possible explanation for the fluorine peak in the SiGe layer might be the presence of vacancy-fluorine clusters, as proposed in the literature [15], [21] to explain fluorine trapping in silicon. Germanium has been reported to efficiently trap 
vacancies in silicon [22], which might lead to higher concentrations of vacancy-fluorine clusters in SiGe than $\mathrm{Si}$ and hence explain the accumulation of fluorine in the SiGe layer seen in Fig. 3. Alternatively, the co-location of the fluorine and boron in the SiGe layer could suggest a chemical interaction between fluorine and boron as has been proposed for fluorine and boron in silicon [13], [16], [23]. If the fluorine-boron interaction in $\mathrm{SiGe}$ was stronger than that seen in $\mathrm{Si}$, this might also explain the accumulation of fluorine in the SiGe layer. Other factors may also influence the fluorine concentration in the SiGe layer, for example strain. Further work is needed to investigate these possibilities.

Several mechanisms have been proposed to explain the suppression of boron diffusion in silicon by fluorine, including the presence of vacancy-fluorine clusters [15], [17], [21] that locally suppress the interstitial concentration, the presence of interstitial-fluorine clusters [12], [24] that suppress the release of interstitials and reduce the backflow of excess interstitials to the surface, and a chemical interaction between boron and fluorine that prevents the interaction of boron with interstitials [13], [16] or reduces the mobility of interstitial boron [23]. Recent work on boron diffusion suppression in silicon [25] has shown that a fluorine peak is present even in samples without a boron marker layer, which indicates that a chemical interaction between boron and fluorine can be discounted. Given the location of the $\mathrm{SiGe}$ layer in the vacancy-rich region of the $\mathrm{P}^{+}$and $\mathrm{F}^{+}$damage profiles, we propose that the fluorine peak in the SiGe layer is due to vacancy-fluorine clusters and the reduction of boron thermal diffusion in $\mathrm{SiGe}$ is due to a suppression of the interstitial concentration in the SiGe layer due to the presence of the clusters. The conventional TED models [26] propose that boron TED is due to interstitials released from extended defects and their subsequent diffusion to the surface or to other extended defects such as dislocation loops. This suggests that the broad fluorine peak in Fig. 2 at a depth of $0.41 \mu \mathrm{m}$ may play a role in the suppression of the boron TED. Further work is needed to investigate this possibility.

\section{CONCLUSION}

In conclusion, a study has been made of the effect of a $\mathrm{F}^{+}$ implant on the diffusion of boron in SiGe. In samples implanted with $\mathrm{F}^{+}$only, the fluorine reduces the boron thermal diffusion by $58 \%$ compared with annealed unimplanted samples. In $\mathrm{SiGe}$ samples implanted with $\mathrm{P}^{+}$and $\mathrm{F}^{+}$, the fluorine completely suppresses boron transient enhanced diffusion and reduces boron thermal diffusion. Fluorine SIMS profiles in SiGe after anneal show a concentration of fluorine in the SiGe layer that is approximately eight times higher than that after implant. This strong accumulation of fluorine in the SiGe layer would be advantageous for the suppression of boron diffusion in devices like $\mathrm{SiGe}$ HBTs, where the boron must be confined within the SiGe layer.

\section{REFERENCES}

[1] B. Jagannathan et al., IEEE Electron Device Lett., vol. 23, pp. 258-260, Mar. 2002.

[2] M. R. Hashim, R. F. Lever, and P. Ashburn, "2D simulation of transient enhanced boron out-diffusion from the base of a SiGe HBT due to an extrinsic base implant," Solid State Electron., vol. 43, pp. 131-140, 1999.
[3] M. Y. Kwong, R. Kasnavi, P. Griffin, J. D. Plummer, and R. W. Dutton, "Impact of lateral source/drain abruptness on device performance," IEEE Trans. Electron Devices, vol. 49, pp. 1882-1890, Dec. 2002.

[4] H. Rücker et al., "Dopant diffusion in C-doped Si and SiGe: Physical model and experimental verification," in IEDM Tech. Dig., 1999, pp. 345-348.

[5] P. Chevalier, C. Fellous, B. Martinet, F. Leverd, F. Saguin, D. Dutartre, and A. Chantre, " $180 \mathrm{GHz} f_{T}$ and $f_{\max }$ self-aligned SiGeC HBT using selective epitaxial growth of the base," in Proc. 33rd Eur. Solid State Device Research Conf., Estoril, Portugal, 2003, pp. 299-302.

[6] R. G. Wilson, "Boron, fluorine and carrier profiles for $\mathrm{B}$ and $\mathrm{BF}_{2}$ implants into crystalline and amorphous Si," Jpn. J. Appl. Phys., vol. 54, pp. 6879-6889, 1983.

[7] K. Ohyu, T. Itoga, and N. Natsuaki, "Advantages of fluorine introduction in boron implanted shallow $p+/ n$ junction formation," Jpn. J. Appl. Phys., vol. 29, pp. 457-462, 1990.

[8] D. Fan, J. M. Parks, and R. J. Jaccodine, "Effect of fluorine on the diffusion of through-oxide implanted boron in silicon," Appl. Phys. Lett., vol. 59, pp. 1212-1214, 1991.

[9] L. Y. Krasnobaev, N. M. Omelyanovskaya, and V. V. Makarov, "The effect of fluorine on the redistribution of boron in ion implanted silicon," Jpn. J. Appl. Phys., vol. 74, pp. 6020-6022, 1993.

[10] T. H. Huang, H. Kinoshita, and D. L. Kwong, "Influence of fluorine preamorphization on the diffusion and activation of low energy implanted boron during rapid thermal annealing," Appl. Phys. Lett., vol. 65, pp. 1829-1831, 1994.

[11] H.-H. Vuong et al., "Influence of fluorine implant on boron diffusion: Determination of process modeling parameters," Jpn. J. Appl. Phys., vol. 77, pp. 3056-3060, 1995.

[12] D. F. Downey, J. W. Chow, E. Ishida, and K. S. Jones, "Effect of flurine on the diffusion of boron in ion implanted silicon," Appl. Phys. Lett., vol. 73, pp. 1263-1265, 1998.

[13] L. S. Robertson and P. N. Warnes et al., "Junction depth reduction of ion implanted boron in silicon through fluorine ion implantation," in Proc. Mater. Res. Soc. Symp. , vol. 610, 2000, pp. B4.2.1-B4.2.6.

[14] N. Ohno, T. Hara, Y. Matsunaga, M. I. Current, and M. Inoue, "Diffusion of ion implanted boron impurities into pre-amorphised silicon," in Mater. Sci. Semicond. Processing, vol. 3, 2000, pp. 221-225.

[15] T. S. Shano, R. Kim, T. Hirose, Y. Furuta, H. Tsuji, M. Furuhashi, and K. Taniquchi, "Realization of ultra-shallow junction: Suppressed boron diffusion and activation by optimized fluorine coimplantation," in IEDM Tech. Dig., 2001, pp. 37.4.1-37.4.4.

[16] A. Mokhberi, R. Kasnavi, P. B. Griffin, and J. D. Plummer, "Fluorine interaction with point defects, boron and arsenic in ion implanted $\mathrm{Si}$," Appl. Phys. Lett., vol. 80, pp. 3530-3532, 2002.

[17] H. A. W. El Mubarek and P. Ashburn, "Reduction of boron thermal diffusion and elimination of boron transient enhanced diffusion in silicon by high energy fluorine implantation," Appl. Phys. Lett., vol. 83, pp. 4134-4136, 2003.

[18] K. Liu, J. Wu, J. Chen, and A. Jain, "Fluorine assisted super-halo for sub-50 nm transistors," IEEE Electron Device Letters, vol. 24, pp. 180-182, Mar., 2003.

[19] H. Fukutome, Y. Momiyama, H. Nakao, T. Aoyama, and H. Arimoto, "Fluorine implantation impact in extension region on the electrical performance of sub-50 nm PMOSFETS," in IEDM Tech. Dig., 2003, pp. 485-488.

[20] M. D. Giles, "Transient phosphorus diffusion below the amorphization threshold," J. Electrochem. Soc., vol. 138, pp. 1160-1165, 1991.

[21] M. Diebel, S. Chakravarthi, C. F. Machala, S. Ekbote, A. Jain, and S T. Dunham, "Investigation and modeling of fluorine co-implantation effects on dopant redistribution," in Proc. Mater. Res. Soc. Symp., 2003, pp. D6.15.1-D6.15.6.

[22] A. Brelot, "Selective trapping of vacancies," in Proc. Defects Semicon ductors, 1972, pp. 191-201.

[23] A. Dusch, J. Marcon, K. Masmoudi, K. Ketata, F. Olivie, M. Benzohra, and M. Ketata, "Influence of fluorine on the simulation of the transient enhanced diffusion of $15 \mathrm{keV} \mathrm{BF}_{2}^{+}$ion implantation into silicon," Nucl. Instrum. Methods Phys. Res. B, Beam Interact. Mater. At., vol. 186, pp. 360-365, 2002.

[24] R. R. Robinson and M. E. Law, "Fluorine diffusion: Models and experiments," in IEDM Tech. Dig., 2002, pp. 883-886.

[25] H. A. W. El Mubarek et al., "Effect of fluorine implantation dose on boron thermal diffusion in silicon," J. Appl. Phys., submitted for publication.

[26] B. Colombeau et al., "Time evolution of the depth profile of $\{311\}$ defects during transient enhanced diffusion in silicon," Appl. Phys. Lett., vol. 83, pp. 1953-1955, 2003. 